\title{
Peripheral Inflammatory Cytokines and Lymphocyte Subset Features of Deceased COVID-19 Patients
}

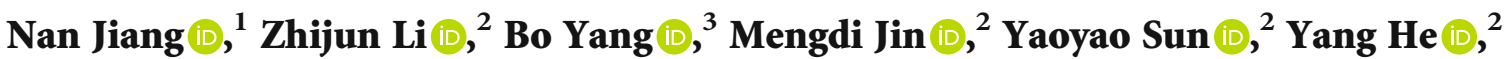

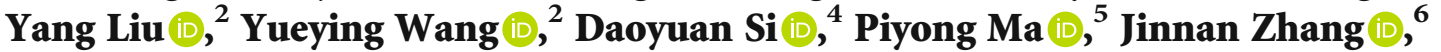 \\ Tianji Liu $\mathbb{}^{1},{ }^{1}$ and Qiong Yu $\mathbb{\circledR}^{2}$ \\ ${ }^{1}$ Department of Emergency, China-Japan Union Hospital of Jilin University, Changchun 130021, China \\ ${ }^{2}$ Department of Epidemiology and Biostatistics, School of Public Health, Jilin University, Changchun 130021, China \\ ${ }^{3}$ Institute of Organ Transplantation, Tongji Hospital, Tongji Medical College, Huazhong University of Science and Technology, \\ Wuhan 430000, China \\ ${ }^{4}$ Department of Cardiology, China-Japan Union Hospital of Jilin University, Changchun 130021, China \\ ${ }^{5}$ Department of Critical Care Unit, China-Japan Union Hospital of Jilin University, Changchun 130021, China \\ ${ }^{6}$ Department of Neurosurgery, China-Japan Union Hospital of Jilin University, Changchun 130021, China
}

Correspondence should be addressed to Tianji Liu; liutj1000@163.com and Qiong Yu; yuqiong@jlu.edu.cn

Received 4 August 2020; Revised 9 December 2020; Accepted 8 January 2021; Published 27 January 2021

Academic Editor: Luis Fernandes

Copyright (c) 2021 Nan Jiang et al. This is an open access article distributed under the Creative Commons Attribution License, which permits unrestricted use, distribution, and reproduction in any medium, provided the original work is properly cited.

Objective. To compare the difference of inflammatory cytokines and lymphocyte subsets between deceased patients and survivors with COVID-19. Methods. This retrospective study included 254 confirmed patients from 10 January to 11 March, 2020, at Tongji Hospital of Wuhan, China. Laboratory and immunologic features were collected and analyzed, and the main outcomes focused on inflammatory cytokines and lymphocyte subsets. Results. A trend of markedly higher levels of inflammatory cytokines as well as lower lymphocyte subset levels in deceased patients was observed compared with survivors. ROC curve analyses indicated that inflammatory cytokines and the decrease levels of T cell, Th (helper T cells) cell, Ts (suppressor T cells) cell, B cell, and NK cell along with Th/Ts ratio increase could be used to predict the death of COVID-19. Multivariate analyses showed that higher levels of IL-6, IL-8, and IL-10 remained significantly correlated with shorter survival time and that the amount of Ts cells was negatively associated with the possibility of death in COVID-19 patients. In conclusion, SARS-CoV-2 would cause lymphopenia and result in decreased lymphocyte subset cells, particularly in Ts cell counts, which further induces hyperinflammatory response and cytokine storm. IL-6, IL-8, IL-10, and Ts cell might be independent predictors for the poor outcome of COVID-19.

\section{Introduction}

SARS coronavirus 2 (SARS-CoV-2) is a member of $\beta$-coronavirus $(\beta-\mathrm{CoV})$ lineage $\mathrm{B}$ belonging to $\mathrm{CoV}$ family, which has been confirmed for causing coronavirus disease 2019 (COVID-19) first identified and confirmed in Wuhan, China, in December 2019 [1, 2]. Genomic analysis indicated that SARS-CoV-2 shares about $80 \%$ identical genome and almost all encoded proteins with human severe acute respira- tory syndrome (SRAS-CoV), while only $50 \%$ genomic identity with middle east respiratory syndrome (MERS-CoV) and more similarities to bat CoVs $[3,4]$. Considering the highly contagious nature from person-to-person and global epidemic of SARS-CoV-2, WHO firstly declared it as a Public Health Emergency of International Concern at January 30th, 2020 [5], and then characterized it as a pandemic at March 11th, 2020 [6]. Currently, there are more than 50 COVID19 vaccine candidates in clinical trials globally, and some 
TABLE 1: Laboratory findings of deceased patients with COVID-19 on admission.

\begin{tabular}{|c|c|c|c|c|c|}
\hline Biomarker & Normal range & All patients (254) & $\begin{array}{l}\text { Median (IQR) } \\
\text { Survivors (203) }\end{array}$ & Nonsurvivors (51) & $P$ value \\
\hline \multirow{3}{*}{ Leucocytes, $\times 10^{9} / \mathrm{L}$} & $3.5-9.5$ & $6.20(4.81-8.93)$ & $5.87(4.64-7.27)$ & $10.66(6.29-13.4)$ & $<0.001$ \\
\hline & Increased & $56(22.0 \%)$ & $26(12.8 \%)$ & $30(58.8 \%)$ & \multirow[t]{2}{*}{$<0.001$} \\
\hline & Decreased & $14(5.5 \%)$ & $12(5.9 \%)$ & $2(3.9 \%)$ & \\
\hline \multirow{3}{*}{ Neutrophils, $\times 10^{9} / \mathrm{L}$} & $1.8-6.3$ & $4.38(3.17-7.26)$ & $3.96(2.80-5.31)$ & $9.48(5.87-12.59)$ & $<0.001$ \\
\hline & Increased & $75(29.5 \%)$ & $37(18.2 \%)$ & $38(74.5 \%)$ & \multirow[t]{2}{*}{$<0.001$} \\
\hline & Decreased & $10(3.9 \%)$ & $9(4.4 \%)$ & $1(2.0 \%)$ & \\
\hline \multirow{2}{*}{ Lymphocytes, $\times 10^{9} / \mathrm{L}$} & $1.1-3.2$ & $0.96(0.64-1.40)$ & $1.09(0.74-1.51)$ & $0.56(0.43-0.73)$ & $<0.001$ \\
\hline & Decreased & $151(59.4 \%)$ & $102(50.2 \%)$ & 49 (96.1\%) & $<0.001$ \\
\hline \multirow{3}{*}{ NLR } & $1.6-5.7$ & $4.8(2.3-9.6)$ & $3.7(2.0-6.1)$ & $15.3(9.6-26.9)$ & $<0.001$ \\
\hline & Decreased & $24(9.4 \%)$ & $24(11.8 \%)$ & - & \multirow[t]{2}{*}{0.003} \\
\hline & Increased & $106(41.7 \%)$ & $57(28.1 \%)$ & 49 (96.1\%) & \\
\hline Monocyte, $\times 10^{9} / \mathrm{L}$ & $0.1-0.6$ & $0.49(0.36-0.63)$ & $0.51(0.40-0.64)$ & $0.37(0.28-0.59)$ & 0.002 \\
\hline \multirow{3}{*}{ Platelets, mean (SD), $\times 10^{9} / \mathrm{L}$} & $125-350$ & $227.1 \pm 101.2$ & $243 \pm 99$ & $164 \pm 85$ & $<0.001$ \\
\hline & Increased & $31(12.2 \%)$ & $30(14.8 \%)$ & $1(2.0 \%)$ & \multirow[t]{2}{*}{$<0.001$} \\
\hline & Decreased & $38(15.0 \%)$ & $21(10.3 \%)$ & $17(33.3 \%)$ & \\
\hline $\mathrm{ESR}, \mathrm{mm} / \mathrm{H}$ & $0-20 \mathrm{~mm} / \mathrm{H}$ & $40(18.5-64.0)$ & $41(20-66)$ & $36(15-63)$ & 0.299 \\
\hline Glu, mmol/L & $4.11-6.05$ & $6.13(5.29-8.07)$ & $5.83(5.16-7.20)$ & $8.99(6.65-11.77)$ & $<0.001$ \\
\hline NT-proBNP, pg/mL & $<738$ & $244(96.2-849.8)$ & $192(74-540)$ & $1235(601-4390)$ & $<0.001$ \\
\hline PCT, ng/mL & $0.02-0.05$ & $0.06(0.03-0.16)$ & $0.04(0.03-0.10)$ & $0.22(0.12-1.01)$ & $<0.001$ \\
\hline cTnI, pg/mL & $\leq 15.6$ & $6.6(2.5-24.2)$ & $4.5(2.2-11.9)$ & $94.7(22.0-908.7)$ & $<0.001$ \\
\hline Myoglobin, ng/mL & $\leq 106$ & $56.2(34.1-119.7)$ & $48.6(31.2-89.4)$ & $160.0(82.6-442.9)$ & $<0.001$ \\
\hline $\mathrm{CK}-\mathrm{MB}, \mathrm{ng} / \mathrm{mL}$ & $\leq 3.4$ & $0.8(0.5-1.8)$ & $0.7(0.4-1.4)$ & $2.8(1.4-7.4)$ & $<0.001$ \\
\hline \multicolumn{6}{|l|}{ Blood biochemistry } \\
\hline ALT, U/mL & $\leq 33$ & $24.5(15.8-42.0)$ & $23(15-40)$ & $29(19-50)$ & 0.023 \\
\hline AST, U/mL & $\leq 32$ & $26.0(19.0-45.0)$ & $24(18-37)$ & $47(30-79)$ & $<0.001$ \\
\hline $\mathrm{TP}, \mathrm{g} / \mathrm{L}$ & $64-83$ & $68.6(64.4-72.8)$ & $69.3(65.4-73.6)$ & $63.8(56.9-70.5)$ & $<0.001$ \\
\hline Albumin, $\mathrm{g} / \mathrm{L}$ & $35-53$ & $33.2(30.5-37.5)$ & $34.6(31.4-38.1)$ & $29.7(25.3-32.5)$ & $<0.001$ \\
\hline Globulin, U/mL & $25-35$ & $34.1(30.6-38.1)$ & $34.0(31.4-38.1)$ & $34.3(31.3-38.6)$ & 0.946 \\
\hline $\mathrm{TBIL}, \mu \mathrm{mol} / \mathrm{L}$ & $\leq 2$ & $10.5(7.2-14.6)$ & $9.5(7.0-13.9)$ & $14.0(9.6-19.2)$ & $<0.001$ \\
\hline DBIL, $\mu \mathrm{mol} / \mathrm{L}$ & $\leq 8$ & $4.4(3.1-6.6)$ & $4.1(3.0-5.7)$ & $6.2(4.4-10.2)$ & $<0.001$ \\
\hline IBIL, $\mu \mathrm{mol} / \mathrm{L}$ & $\leq 12.9$ & $5.4(4.1-8.2)$ & $5.2(3.9-7.9)$ & $6.5(4.5-9.2)$ & 0.046 \\
\hline ALP, U/L & $35-105$ & $71(55-93)$ & $67(55-87)$ & $84(58-122)$ & 0.003 \\
\hline GGT, U/L & $6-42$ & $30(19-54.5)$ & $29(18-52)$ & $40(20-81)$ & 0.046 \\
\hline $\mathrm{TC}, \mathrm{mmol} / \mathrm{L}$ & $<5.18$ & $3.77(3.12-4.41)$ & $3.9(3.3-4.5)$ & $3.2(2.7-3.9)$ & $<0.001$ \\
\hline $\mathrm{LDH}, \mathrm{U} / \mathrm{L}$ & $135-214$ & $292.5(227.8-453.0)$ & $265(214-351)$ & $532(469-760)$ & $<0.001$ \\
\hline Creatinine, $\mu \mathrm{mol} / \mathrm{L}$ & $45-85$ & $74(60-92.5)$ & $71(59-88)$ & $88(69-160)$ & $<0.001$ \\
\hline \multirow[t]{2}{*}{$\mathrm{CRP}, \mathrm{mg} / \mathrm{L}$} & $<1$ & $28.1(4.8-92.5)$ & $13.8(2.5-61)$ & $102.9(62.5-187.1)$ & $<0.001$ \\
\hline & Increased & $216(85.0 \%)$ & $165(86.8 \%)$ & $51(100.0 \%)$ & 0.003 \\
\hline \multicolumn{6}{|l|}{ Coagulation function } \\
\hline PT, s & $11.5-14.5$ & $14.0(13.4-14.9)$ & $13.8(13.2-14.3)$ & $15.5(14.6-18.1)$ & $<0.001$ \\
\hline INR & $0.8-1.2$ & $1.08(1.01-1.17)$ & $1.05(0.99-1.11)$ & $1.22(1.14-1.47)$ & $<0.001$ \\
\hline Fibrinogen, $\mathrm{g} / \mathrm{L}$ & $2-4$ & $5.00(3.42-6.08)$ & $5.08(3.71-6.13)$ & $3.92(2.61-5.82)$ & 0.004 \\
\hline APTT, s & $29-42$ & $39.1(36.1-43.4)$ & $39(36.2-43.0)$ & $39.1(35.7-45.1)$ & 0.984 \\
\hline D-dimer, U/mL FEU & $<0.5$ & $1.46(0.57-4.05)$ & $1.18(0.48-2.18)$ & $15.01(1.77-21.00)$ & $<0.001$ \\
\hline \multicolumn{6}{|l|}{ Urine routine } \\
\hline Urine protein, $\mathrm{n} / N(\%)$ & - & $123 / 225(54.7 \%)$ & $84 / 185(45.4 \%)$ & $39 / 40(97.5 \%)$ & $<0.001$ \\
\hline USG, n, median (IQR) & $1.01-1.025$ & $225,1.016(1.012-1.022)$ & $185,1.015(1.011-1.020)$ & $40,1.021(1.018-1.028)$ & $<0.001$ \\
\hline $\mathrm{pH}, \mathrm{n}$, median (IQR) & $4.5-8.0$ & $225,6.5(6.0-6.5)$ & $185,6.5(6.0-6.75)$ & $40,6.0(6.0-6.5)$ & 0.039 \\
\hline $\mathrm{KET}, \mathrm{n} / \mathrm{N}(\%)$ & - & $37 / 225(16.4 \%)$ & $18 / 185(9.7 \%)$ & $19 / 40(47.5 \%)$ & $<0.001$ \\
\hline
\end{tabular}


TABLE 1: Continued.

\begin{tabular}{|c|c|c|c|c|c|}
\hline Biomarker & Normal range & All patients (254) & $\begin{array}{l}\text { Median (IQR) } \\
\text { Survivors (203) }\end{array}$ & Nonsurvivors (51) & $P$ value \\
\hline URO, n/N (\%) & - & $12 / 225(5.3 \%)$ & $6 / 185(3.2 \%)$ & $6 / 40(15.0 \%)$ & 0.009 \\
\hline \multicolumn{6}{|l|}{ Arterial blood gas } \\
\hline $\mathrm{pH}, N$, median (IQR) & $7.35-7.45$ & $77,7.42(7.39-7.46)$ & $58,7.41(7.39-7.45)$ & $19,7.42(7.38-7.48)$ & 0.382 \\
\hline $\mathrm{PaCO} 2, \mathrm{mmHg}$ & $35-45$ & $76,38.8(34.4-43.2)$ & $57,40.7(37.4-43.7)$ & $19,31.9(25.3-37.4)$ & $<0.001$ \\
\hline $\mathrm{PaO} 2, \mathrm{mmHg}$ & $80-100$ & $76,117(78.5-174.8)$ & $57,134(87.2-187)$ & $19,68(51.7-121)$ & $<0.001$ \\
\hline $\mathrm{SB}, \mathrm{mmol} / \mathrm{L}$ & $21-25$ & $75,25.3(23.5-27.2)$ & $56,25.4(23.9-27.3)$ & $19,22.2(19.0-25.3)$ & 0.001 \\
\hline $\mathrm{BE}, \mathrm{mmol} / \mathrm{L}$ & $-3-3$ & $76,0.8(-1.3-3.2)$ & $57,1.3(-0.5-3.3)$ & $19,-3.9(-8.1-0.2)$ & 0.001 \\
\hline $\mathrm{TCO} 2, \mathrm{mmol} / \mathrm{L}$ & $24-32$ & $75,22.5(20.2-24.2)$ & $56,23.0(21.4-24.4)$ & $19,17.8(16.0-22.5)$ & 0.001 \\
\hline $\mathrm{SaO} 2, N$, median (IQR) & $91.9-99 \%$ & $76,98.6(94.0-99.6)$ & 57, $99.1(97.2-99.6)$ & $19,89.8(85.1-97.5)$ & $<0.001$ \\
\hline
\end{tabular}

NLR: neutrophil-to-lymphocyte ratio; ESR: erythrocyte sedimentation rate; Glu: glucose; ALT: alanine aminotransferase; AST: aspartate aminotransferase; ALP: alkaline phosphatase; TP: total protein; TBIL: total bilirubin; DBIL: direct bilirubin; IBIL: indirect bilirubin; ALP: alkaline phosphatase; GGT: gammaglutamyl transpeptidase; TC: total cholesterol; LDH: lactate dehydrogenase; CRP: C-reactive protein; NT-proBNP: N-terminal of the prohormone brain natriuretic peptide; PCT: procalcitonin; cTnI: cardiac troponin I; CK-MB: creatine kinase-M; PT: prothrombin time; INR: international normalized ratio; APTT: activated partial thromboplastin time; USG: urine specific gravity; KET: urine ketone body; URO: urobilinogen; PaCO2: partial pressure of carbon dioxide; $\mathrm{PaO} 2$ : arterial partial pressure of oxygen; $\mathrm{SB}$ : standard bicarbonate; $\mathrm{BE}$ : base excess of extracellular fluid; TCO2: total carbon dioxide; SaO2: oxygen saturation; $N$ : number of patients; IQR: interquartile range.

vaccines have been approved for emergency use in United Kingdom, China, Arab nations (the United Arab Emirates, Bahrain, and Egypt), Republic of Chile, Canada and US, and so on [7].

Previous studies demonstrated that SARS-CoV-2 infection would cause severe respiratory symptoms, lymphopenia, increased levels of peripheral inflammatory cytokines, and cytokine storm which could be related with high severity and mortality of COVID-19 [8-12]. Besides, lymphocyte subsets play an important functional role in the maintenance of humoral and cytotoxic immunity [13]. Recently, several studies had investigated the association of immunological features and lymphocyte subset alteration with the disease severity in COVID-19, whose results found SARS-CoV-2 might have a main impact on $\mathrm{T}$ lymphocytes, especially helper T (Th) and suppressor T (Ts) cells [13-15]. Decreased Ts cells might be an independent biomarker for severe COVID-19, and decreased Ts and B cells as well as increased $\mathrm{Th} / \mathrm{Ts}$ ratio might be the independent predictors of poor treatment efficacy [13]. However, there is still insufficient knowledge about inflammatory cytokines, lymphocyte subsets, and immune response associated with the death of COVID-19.

In our study, we mainly aimed to compare and elucidate the difference and clinical significance of inflammatory cytokines and lymphocyte subsets between deceased COVID-19 patients and survivors, which might help further demonstrate the immunological effect in deceased COVID-19.

\section{Material and Methods}

2.1. Study Design and Population. We retrospectively recruited 254 laboratory-confirmed COVID-19 patients from 10 January to 11 March, 2020, at Tongji Hospital of Wuhan, China. All patients in the study have been confirmed with no infection of HBV, HCV, and HIV. Ethical Committee of Tongji Hospital of Huazhong University of Science and Technology (No.TJ-IRB20200364) and China-Japan Union
Hospital of Jilin University (No.2020032607) approved the study and waived the written informed consent for rapid emerging infections.

2.2. Data Collection. All cases were confirmed on admission by nucleic acid and antibody tests. Information from electronic medical records was retrospectively collected and extracted, including demographic characteristics, medical history, routine blood and urine tests, biochemical detection, and inflammatory cytokines and lymphocyte subset tests. All data were extracted with the unified data collection form by two independent researchers. The severity of patients was classified by the Novel Coronavirus Pneumonia Diagnosis and Treatment Guidance (Seventh revised trial version) [16].

2.3. Statistical Analysis. Categorical variables were described as percentages and compared by chi-squared or Fisher's exact test; continuous variables were described as means (SD) or medians (interquartile range (IQR)) and compared by nonparametric comparative tests or $t$-tests. Spearman rank correlation coefficient was used to analyze the correlations between paired data. Area under the receiver operating characteristic curve (AUROC) was performed to evaluate the predictive values of peripheral inflammatory cytokines and lymphocyte subsets in predicting the mortality of COVID-19. Kaplan-Meier analyses with Logrank test were performed to assess the clinical significance for survival time between high and low levels of inflammatory cytokines. Multivariate Cox regression model was performed to determine the predictive factors for deceased COVID-19. All statistical analyses were accomplished by the SPSS 22.0 and R 3.6.1 software, and results with $P<$ 0.05 were considered statistical significant.

\section{Results}

3.1. Demographics and Baseline Characteristic of Deceased Cases of COVID-19. 254 patients were included with 51 
TABLE 2: Inflammatory cytokines and lymphocyte subsets in deceased patients with COVID-19 on admission.

\begin{tabular}{|c|c|c|c|c|c|}
\hline Biomarker & Normal range & All patients (254) & $\begin{array}{l}N, \text { median (IQR) } \\
\text { Survivors (203) }\end{array}$ & Nonsurvivors (51) & $P$ value \\
\hline \multicolumn{6}{|l|}{ Inflammatory cytokines } \\
\hline \multirow[t]{2}{*}{ Interleukin- $1 \beta, \mathrm{pg} / \mathrm{mL}$} & $<5$ & $254,5(5-5)$ & $203,5(5-5)$ & $51,5(5-5)$ & 0.235 \\
\hline & $223-710$ & $254,644(387-1105)$ & $203,541(350.0-868.0)$ & $51,1220(949-1861)$ & $<0.001$ \\
\hline \multirow[t]{2}{*}{ Interleukin-2R, $\mathrm{U} / \mathrm{mL}$} & Decreased & $19(7.5 \%)$ & $19(9.4 \%)$ & - & $<0.001$ \\
\hline & Increased & $120(47.2)$ & $112(55.2)$ & $8(15.7 \%)$ & \\
\hline \multirow{2}{*}{ Interleukin-6, pg/mL } & $<7$ & $254,8.15(2.00-40.47)$ & $203,4.9(1.5-19.3)$ & $51,58.5(26.88-137.48)$ & $<0.001$ \\
\hline & Increased & $136(53.5 \%)$ & $86(42.4 \%)$ & $50(98.0 \%)$ & $<0.001$ \\
\hline \multirow{2}{*}{ Interleukin-8, pg/mL } & $<62$ & $254,11.6(5.1-24.0)$ & $203,8.3(5.0-18.0)$ & $51,29.8(20.6-70.7)$ & $<0.001$ \\
\hline & Increased & $20(7.9 \%)$ & $6(3.0 \%)$ & $14(27.5 \%)$ & $<0.001$ \\
\hline \multirow{2}{*}{ Interleukin-10, $\mathrm{pg} / \mathrm{mL}$} & $<9.1$ & $254,5(5-6.4)$ & $203,5(5-5)$ & $51,9.8(5.2-18.3)$ & $<0.001$ \\
\hline & Increased & $49(19.3 \%)$ & $20(9.9 \%)$ & $29(56.9 \%)$ & $<0.001$ \\
\hline \multirow{2}{*}{ TNF- $\alpha, p g / m L$} & $<8.1$ & $254,7.5(5.2-11.2)$ & $203,6.9(4.7-10.3)$ & $51,10.4(7.5-14.8)$ & $<0.001$ \\
\hline & Increased & $93(36.6 \%)$ & $65(32.0 \%)$ & $28(54.9 \%)$ & 0.003 \\
\hline \multicolumn{6}{|l|}{ Lymphocyte subsets } \\
\hline $\mathrm{T}$ cells $+\mathrm{B}$ cells $+\mathrm{NK}$ cells, $\mathrm{n} / \mu \mathrm{L}$ & - & $137,1309.0(862.5-1612.5)$ & $118,1394(1052.5-1654.2)$ & $19,333(171-748)$ & $<0.001$ \\
\hline \multirow{2}{*}{$\mathrm{T}$ cells, $\mathrm{n} / \mu \mathrm{L}$} & $955-2860$ & $137,939(534.5-1155.5)$ & $118,976(753.8-1188.2)$ & $19,201(122-392)$ & $<0.001$ \\
\hline & Decreased & $71 / 137(51.8 \%)$ & $53 / 118(44.9 \%)$ & $18 / 19(94.7 \%)$ & $<0.001$ \\
\hline \multirow{2}{*}{$\mathrm{B}$ cells, $\mathrm{n} / \mu \mathrm{L}$} & $90-560 / \mu \mathrm{L}$ & $137,158.0(81.5-250.5)$ & $118,167.5(100-254.5)$ & $19,41(30-126)$ & $<0.001$ \\
\hline & Decreased & $39 / 137(28.5 \%)$ & $27 / 118(22.9 \%)$ & $12 / 19(63.2 \%)$ & $<0.001$ \\
\hline \multirow{2}{*}{ Th cells, $\mathrm{n} / \mu \mathrm{L}$} & $550-1440 / \mu \mathrm{L}$ & $137,562.0(330.0-761.5)$ & $118,606.5(466-796)$ & $19,147(84-249)$ & $<0.001$ \\
\hline & Decreased & $65 / 137(47.4 \%)$ & $48 / 118(40.7 \%)$ & $17 / 19(89.5 \%)$ & $<0.001$ \\
\hline \multirow{2}{*}{ Ts cells, $\mathrm{n} / \mu \mathrm{L}$} & $320-1250 / \mu \mathrm{L}$ & $137,270.0(174.5-387.0)$ & $118,294.5(233.8-406.5)$ & $19,54(20-124)$ & $<0.001$ \\
\hline & Decreased & $85 / 137(62.0 \%)$ & $66 / 118(55.9 \%)$ & $19 / 19(100.0 \%)$ & $<0.001$ \\
\hline \multirow{2}{*}{ NK cells, $\mathrm{n} / \mu \mathrm{L}$} & $150-1100 / \mu \mathrm{L}$ & $137,153.0(95.0-253.5)$ & $118,172.5(122-263.8)$ & $19,35(10-70)$ & $<0.001$ \\
\hline & Decreased & $64 / 137(46.7 \%)$ & $47 / 118(39.8 \%)$ & $17 / 19(89.5 \%)$ & $<0.001$ \\
\hline \multirow{2}{*}{$\mathrm{Th} / \mathrm{Ts}$ ratio } & $0.71-2.78$ & $137,2.06(1.52-2.70)$ & $118,2.00(1.48-2.54)$ & $19,3.32(1.87-5.44)$ & $<0.001$ \\
\hline & Increased & $29 / 137(21.2 \%)$ & $19 / 118(16.1 \%)$ & $10 / 19(52.6 \%)$ & $<0.001$ \\
\hline
\end{tabular}

$N$ : number of patients; IQR: interquartile range; T cells: CD3 + CD19- T cells; B cells: CD3-CD19+ T cells; Th, helper T cells: CD3 + CD4+ T cells; Ts, suppressor T cells: CD3 + CD8+ T cells; NK cells: CD3-/CD16 + CD56+ T cells.

(20.1\%) deceased. The median age of all cases was 67 years (IQR, 58-73) and 70 years (IQR, 64-76) for deceased patients. Male patients were $130(51.2 \%)$ including 32 $(62.7 \%)$ deceased cases. The occurrence of any comorbidities in all patients reached $57.4 \%$ and $58.8 \%$ in deceased patients. Hypertension (39.6\%) and diabetes (19.8\%) were the most common comorbidities. Fever (85.1\%), cough (85.1\%), dyspnea (66.0\%), expectoration (64.4\%), myalgia or fatigue $(63.4 \%)$, and chest tightness (53.9\%) were most common symptoms; less common manifestations included nausea or vomiting $(29.7 \%)$, sore throat $(29.7 \%)$, abdominal pain $(27.7 \%)$, and hemoptysis $(27.5 \%)$. The median of hospitalization time was 22 days (IQR 12-29) in all patients, 9 days (IQR 5-16) in deceased patients, and 25 days (IQR 16-30) in survivors.

\subsection{Laboratory Findings of Deceased COVID-19 Patients on} Admission. Compared with normal range, levels of leucocytes and neutrophils in deceased patients were significantly elevated above upper limit of normal range (Table 1). The counts of lymphocytes were all significantly decreased below lower limit of normal range in deceased patients. Leukocytes, neutrophils, lymphocytes, and platelets were decreased in 14 (5.5\%), 10 (3.9\%), 151 (59.4\%), and 38 (15.0\%) patients. The number of patients who developed lymphopenia in deceased cases was 49 (96.1\%). Counts of leucocytes, neutrophils, monocytes, and neutrophil-to-lymphocyte ratio (NLR) in deceased patients were markedly higher than survivors (all $P<0.001$ ), while levels of lymphocytes and platelets were all significantly lower in deceased patients (Table 1).

Levels of Glu, ALT, AST, ALP, and GGT were all significantly elevated in deceased cases (all $P<0.001$ ) (Table 1). TP, albumin, and TC levels were all markedly lower in deceased cases (all $P<0.001$ ). LDH, CRP, D-dimer, NT-proBNP, PCT, and cTnI concentrations were all markedly increased in deceased cases (all $P<0.001$ ) (Table 1).

In routine urine tests, the positive rates of urine protein, urine ketone body (KET), and urobilinogen (URO) were $54.6 \%, 16.4 \%$, and $5.3 \%$, respectively (Table 1 ). Compared with survivors, those positive rates of deceased patients were significantly higher (all $P<0.001$ ). Urine specific gravity (USG) and $\mathrm{pH}$ levels of all patients were within the normal 

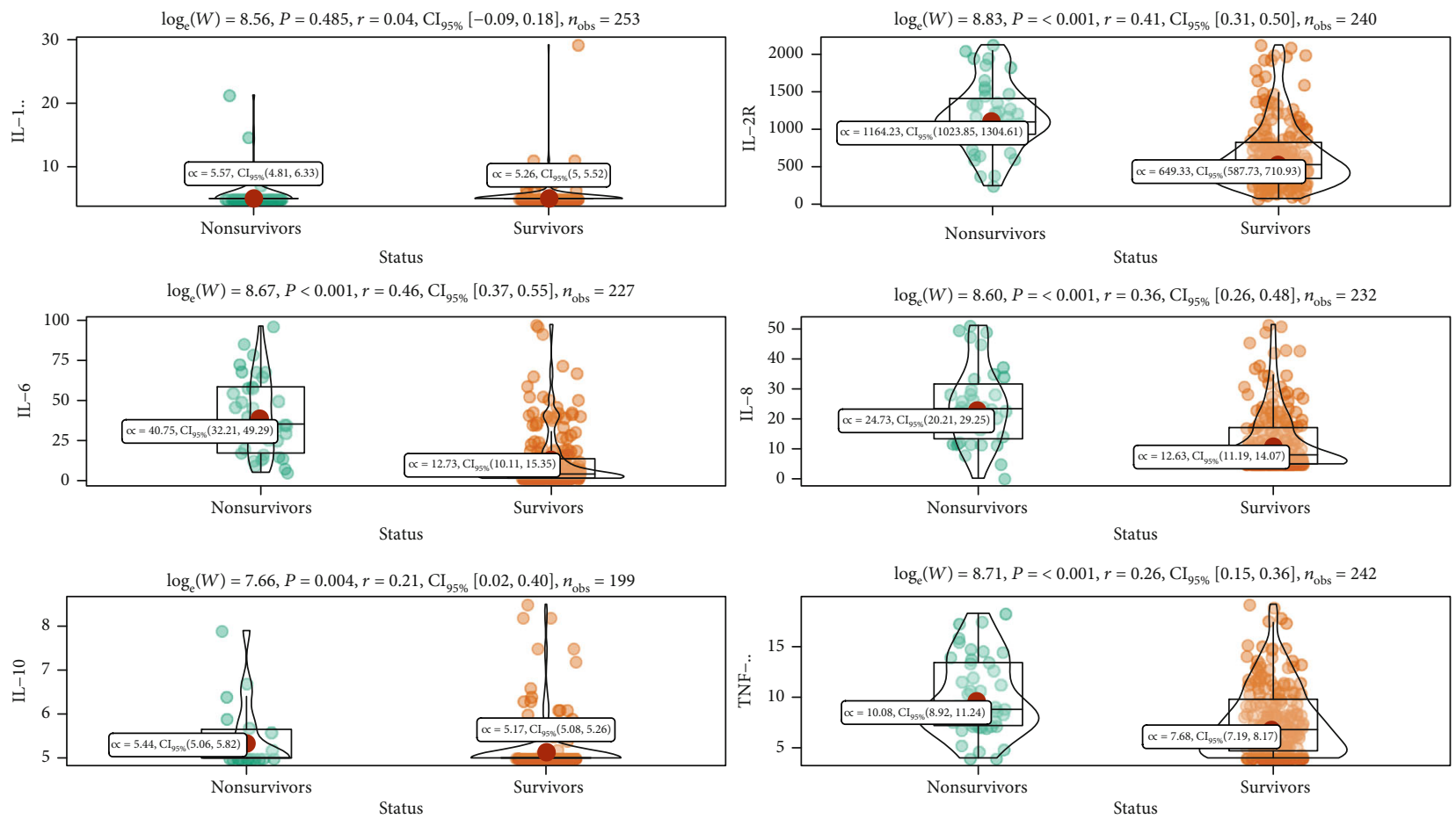

FIgURE 1: Peripheral inflammatory cytokine levels between survivors and nonsurvivors.
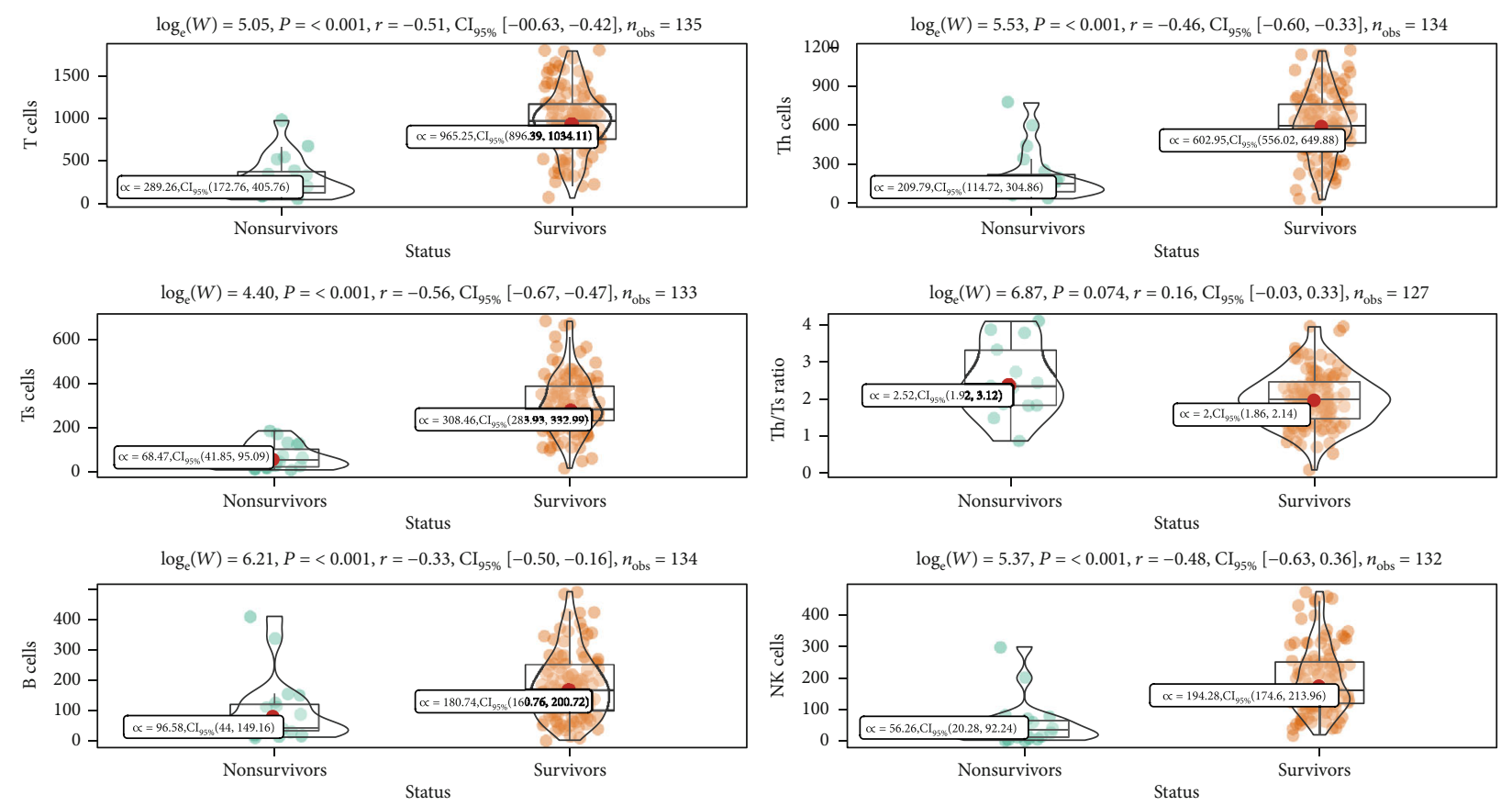

FIGURE 2: Peripheral lymphocyte subset counts between survivors and nonsurvivors.

range. However, the level of USG in deceased cases was significantly elevated (all $P<0.001$ ) while $\mathrm{pH}$ levels decreased $(P<0.05)$.

Blood gas analyses showed that the median arterial partial pressure of oxygen level in deceased patients was $68 \mathrm{mmHg}$, and the median of partial pressure of carbon dioxide was $31.9 \mathrm{mmHg}$. Total partial pressure of carbon dioxide, arterial partial pressure of oxygen, standard bicarbonate, base excess of extracellular fluid, total carbon dioxide, and oxygen saturation were significantly lower in deceased patients than in survivors (all $P<0.05)$ (Table 1).

3.3. Peripheral Inflammatory Cytokines and Lymphocyte Subset Levels with Deceased COVID-19. The level of 


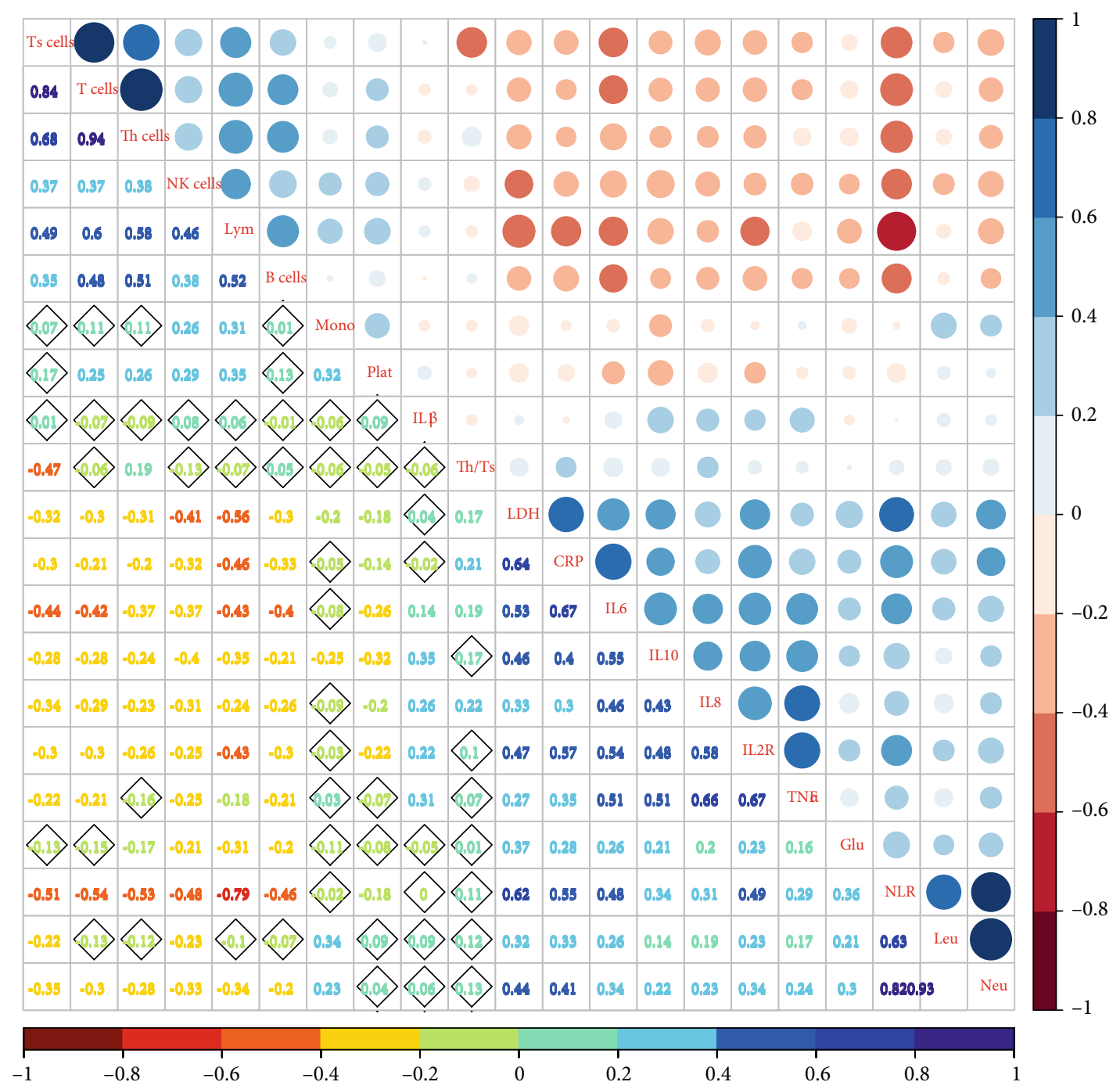

FIGURE 3: Correlation analysis of peripheral inflammatory cytokines and lymphocyte subsets in COVID-19. (Blue means positive correlation, red means negative correlation, circle size represents for strength of correlation, the number in plot means correlation coefficient, and diamond means no statistical significance.)

interleukin-1 $\beta$ (IL- $1 \beta)$ was undetectable $(<5 \mathrm{pg} / \mathrm{mL})$ in almost all patients so that no statistical significance was observed between groups (Table 2). Levels of interleukin2R (IL-2R), interleukin-6 (IL-6), interleukin-8 (IL-8), interleukin-10 (IL-10), and tumor necrosis factor $\alpha$ (TNF$\alpha$ ) on admission were significantly elevated in 120 (47.2\%), 136 (53.5\%), 20 (7.9\%), 49 (19.3\%), and 93 (36.6\%) patients (Table 2). Compared with survivors, these levels were significantly higher in deceased patients (all $P<0.001$ ) (Table 2, Figure 1).

Total counts of $\mathrm{T}$ cells and suppressor $\mathrm{T}(\mathrm{Ts})$ cells were both below lower limit of normal ranges, while counts of $\mathrm{B}$ cells, helper T (Th) cells, Ts cells, NK cells, and Th/Ts ratio were within the normal limits (Table 2). Counts of lymphocytes and $\mathrm{T}$ cell subsets were significantly decreased in deceased cases (all $P<0.001$ ). Th/Ts ratios were significantly elevated beyond upper limit of normal range (3.32 vs. $2.00 / \mu \mathrm{L}, P<0.001)$. Counts of T, B, Th, Ts, and NK cells were decrease in $71 / 137$ (51.8\%), 39/137 (28.5\%), 65/137 (47.4\%), $85 / 137(62.0 \%)$, and $64 / 137(46.7 \%)$ cases. Th/Ts ratio was increased in $29(21.2 \%)$ patients. Meanwhile, counts of $\mathrm{T}$, $\mathrm{B}$, Th, Ts, and NK cells were markedly lower in deceased cases, but Th/Ts ratio was higher (all $P<0.001$ ) (Table 2, Figure 2).

3.4. Correlation Analysis between Cytokine Profiles and Lymphocyte Subsets in COVID-19. Total counts of T, Ts, B, and NK cells were negatively related with levels of $\mathrm{LDH}$, CRP, IL-2R, IL-6, IL-8, IL-10, and TNF- $\alpha$ (all $P<0.05$ ). Except for TNF- $\alpha(P=0.064)$, counts of Th cells was negatively correlated with numbers of neutrophils $(P<0.001)$ and platelets $(P=0.002)$ and concentrations of CRP $(P=0.002), \quad \mathrm{LDH} \quad(P<0.001), \quad \mathrm{CRP} \quad(P=0.023), \quad \mathrm{IL}-2 \mathrm{R}$ $(P=0.002)$, IL-6 $(P<0.001)$, IL-8 $(P=0.008)$, and IL-10 $(P=0.006)$. Total numbers of T, Ts, and NK cells were also negatively correlated with neutrophil counts (all $P<0.001$ ), 


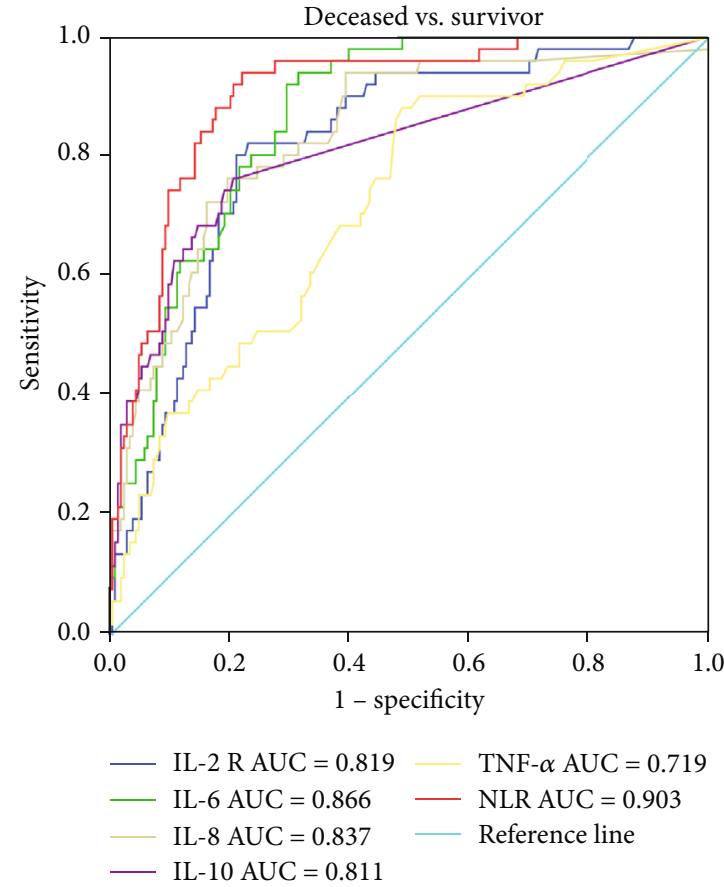

(a)

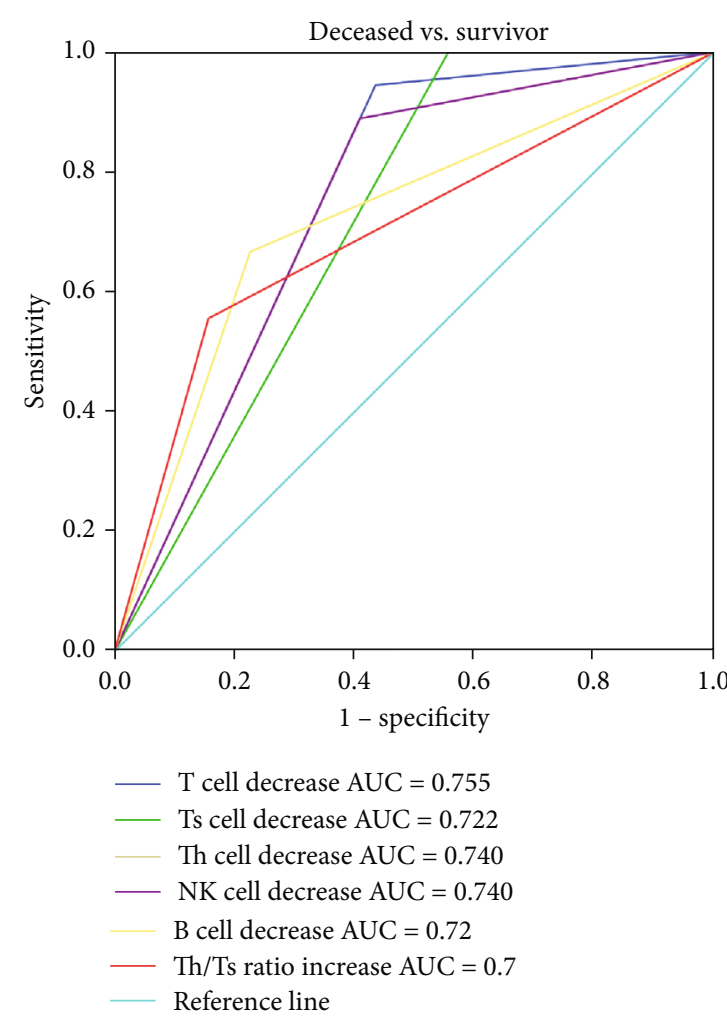

(b)

FIGURE 4: ROC curve of inflammatory cytokines (a) and lymphocyte subsets (b) in deceased COVID-19 patients on admission.

and Ts, B, and NK cells with leucocytes (all $P<0.05$ ). Numbers of $\mathrm{B}$ and NK cells were negatively correlated with glucose level $(P<0.05)$. NK cell count was also negatively correlated with numbers of monocytes $(P=0.002)$ and platelets $(P=0.002)$ (Figure 3). Details of the correlation between all the collected data are shown in Supplementary file see (available here).

3.5. Predictive Values of Potential Markers for Distinguishing Deceased COVID-19. ROC curve analyses indicated that the plasma levels of inflammatory cytokines could predict the mortality of COVID-19 as all AUCs were above 0.7 (Figure 4(a)). ROC curve analyses in lymphocyte subsets indicated that the decrease of T, Th, Ts, B, and NK cell counts along with $\mathrm{Th} / \mathrm{Ts}$ ratio increase could be used to predict the occurrence of death in COVID-19 patients (all $P<0.05$ ) (Figure 4(b)).

Kaplan-Meier survival curves showed that higher IL-2R, IL-6, IL-8, IL-10, and TNF- $\alpha$ levels were significantly correlated with reduced survival time in COVID-19 (all $P<$ 0.001) (Figure 5).

Multivariate Cox model analyses showed that higher levels of IL-6, IL-8, and IL-10 remained significantly correlated with shorter survival time (IL-6: $\mathrm{HR} 26.22, P=0.001$; IL-8: HR 3.11, $P=0.004$; IL-10: HR 2.94, $P<0.001$ ), and Ts cell count $(/ \mu \mathrm{L})$ was negatively associated with COVID-19related death (HR 0.98, $P=0.049$ ) (Figure $6(\mathrm{~b})$ ), indicating that IL-6, IL-8, and IL-10 levels and Ts cell count could be the independent risk factors to predict the possibility of death of COVID-19.

\section{Discussion}

Previous studies suggested that several coronavirus infections could cause sustained responses of cytokine storm and dysregulation in lymphocyte subset levels, resulting in high incidence of immune disorders and mortality $[13,17]$. Although a number of researches on clinical and epidemiological characteristics have been published $[9,11,18]$, there is still insufficient knowledge of the potential mechanism in COVID-19. Thus, elucidating the features of peripheral inflammatory cytokines and lymphocyte subsets would be important for exploring the immune response mechanism of COVID-19.

Our laboratory findings showed that most patients presented lymphopenia, increased neutrophil count, and elevated levels of glucose, NT-proBNP, procalcitonin, cTnI, ALT, AST, LDH, CRP, and D-dimer. In deceased cases, there were significantly higher numbers of leucocytes and neutrophils and markedly higher levels of NLR, glucose, NTproBNP, procalcitonin, cTnI, ALT, AST, LDH, CRP, and $\mathrm{D}$-dimer than survivors but significantly lower numbers of lymphocytes, monocyte, and platelets. Leukocytosis, lymphopenia, and increased concentration of acute phase reactants were more commonly seen in deceased cases, which could promote death from COVID-19. Patients with uncontrolled blood glucose or diabetes had longer median length of 

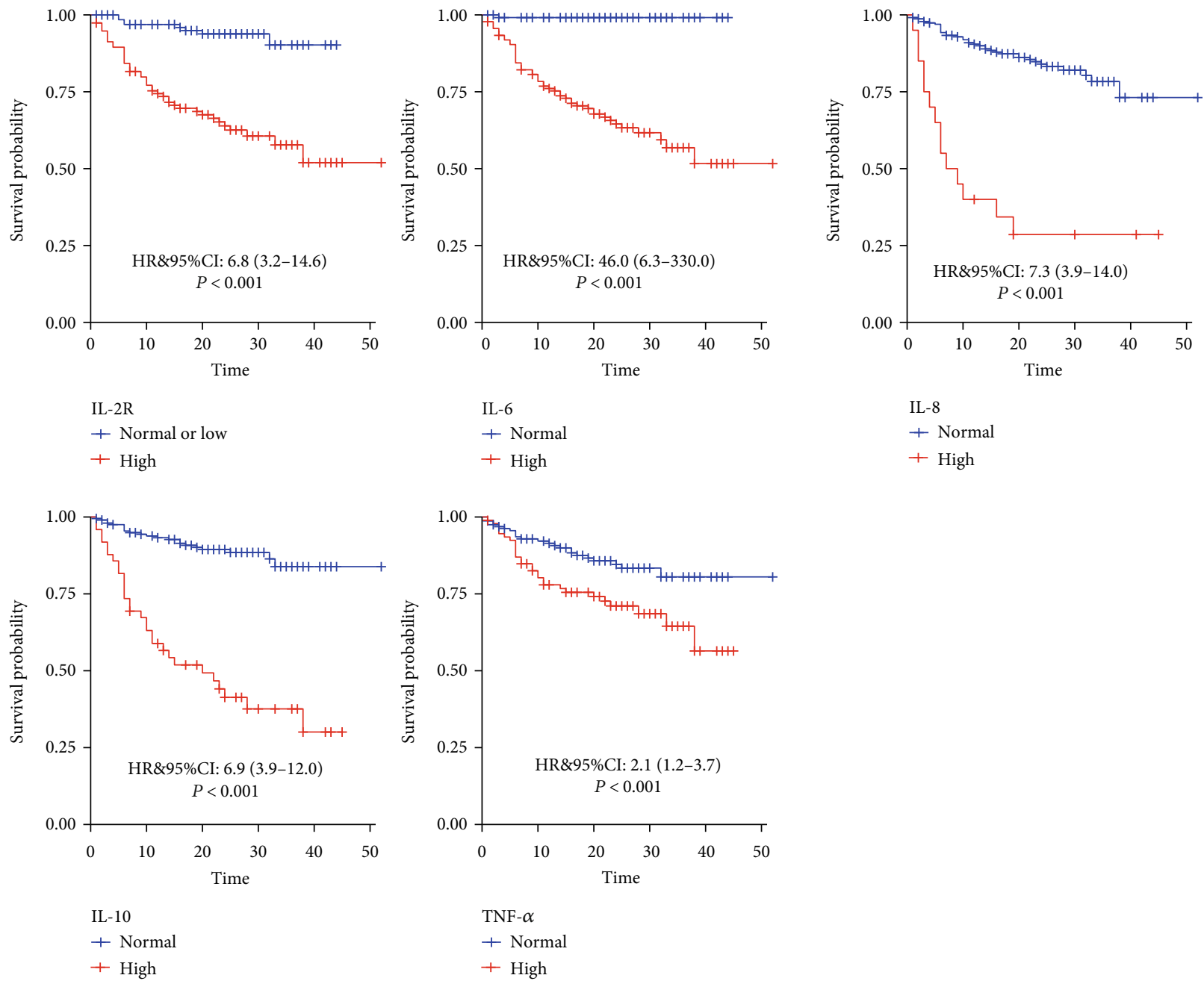

FIGURE 5: Survival according to the levels of inflammatory cytokines in COVID-19.

stay and significantly higher mortality than those with wellcontrolled blood glucose or nondiabetes [19-21]. The increased neutrophil count, NLR, and D-dimer might indicate higher incidence of poor clinical outcomes [10, 14, 22] and myocardial injury which might be induced by inflammation was related with cardiac insufficiency, arrhythmias, and adverse endpoints [23]. Recently, one study using machine learning tools has identified 3 indicators (LDH, lymphocyte, and hs-CRP) which could predict the death of COVID-19 more than 10 days in advance with the accuracy of over $90 \%$ and found that high levels of $\mathrm{LDH}$ require immediate medical attention in patients [24]. Previous studies had demonstrated that acute phase reactants play key roles in the diagnosis and prediction of systemic inflammation and infection as well as the prognosis in severe patients of SARS and MERS [25-27], which were consistent with our findings. Further research on acute phase reactants would help with early diagnosis, prediction of disease process, and clinical outcomes.

Our results showed that all inflammation cytokine levels were substantially elevated, which is characterized as cytokine storm, to be significantly higher in most of the deceased cases similar with SARS and MERS results $[28,29]$. Previous studies had suggested that inflammation cytokines and chemokines hold vital positions in cytokine storm [30]. Elevated concentrations of IL-6, IL-8, and IL-10 remained significantly correlated with shorter survival time on multivariate analyses, indicating that the association between baselines of IL-6, IL-8, and IL-10 and shorter survival time in COVID-19 might be the independent predictor of poor clinical outcomes and an addition to prognostic factors. Elevated concentration of IL- 6 had been indicated as a stable indicator for the progression and adverse endpoint of COVID-19, and IL- 6 and IL-10 were significantly related with the positivity duration of SARS-CoV-2 [31, 32], which were consistent with our findings. Previous studies showed that IL-6R antagonist tocilizumab could reverse the cytokine storm [33], and specifically blockading the signaling pathways regulated by IL-6 might be a promising method to reduce inflammationrelated injuries and the mortality $[34,35]$. IL-10 has a major anti-inflammatory effect regulated by JAK-STAT pathway [36], produced by antigen presentation cells (APC) including dendritic cells, macrophages, and Th cells [36, 37]. Higher IL-8 levels were found in deceased cases that might induce 


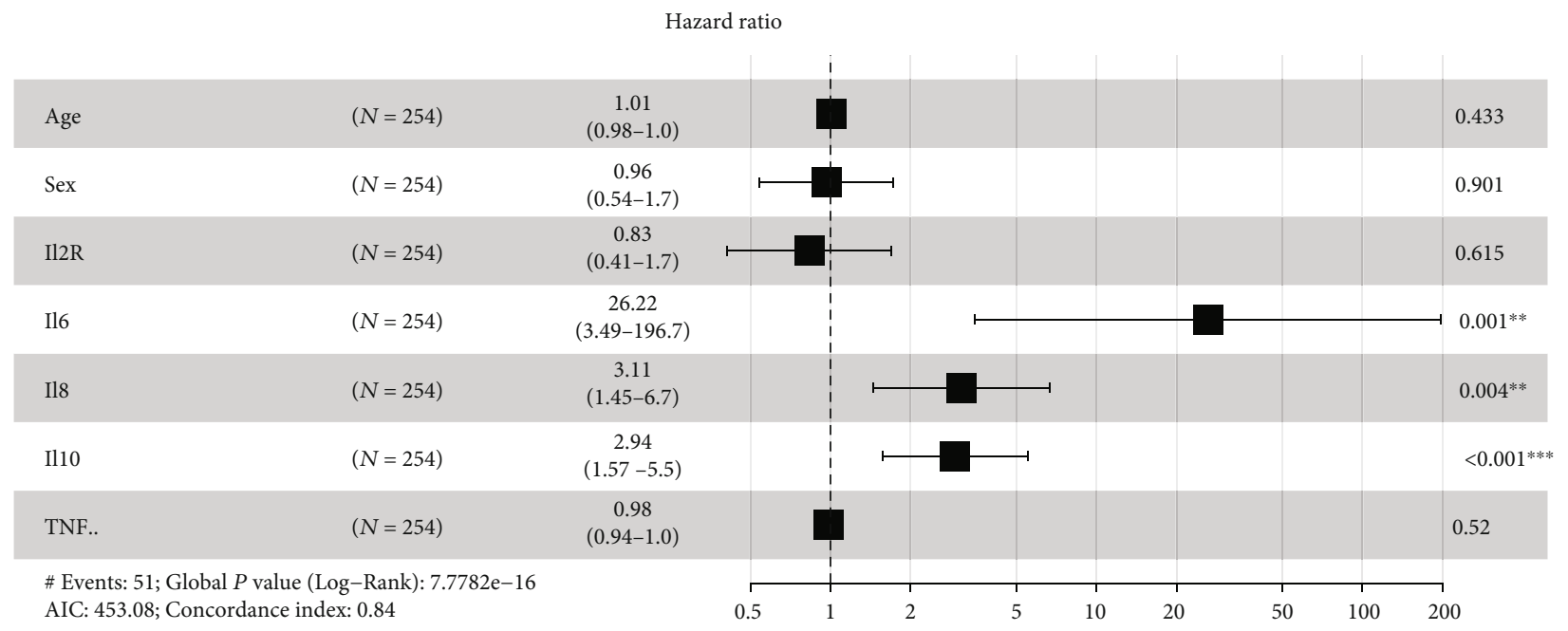

(a)

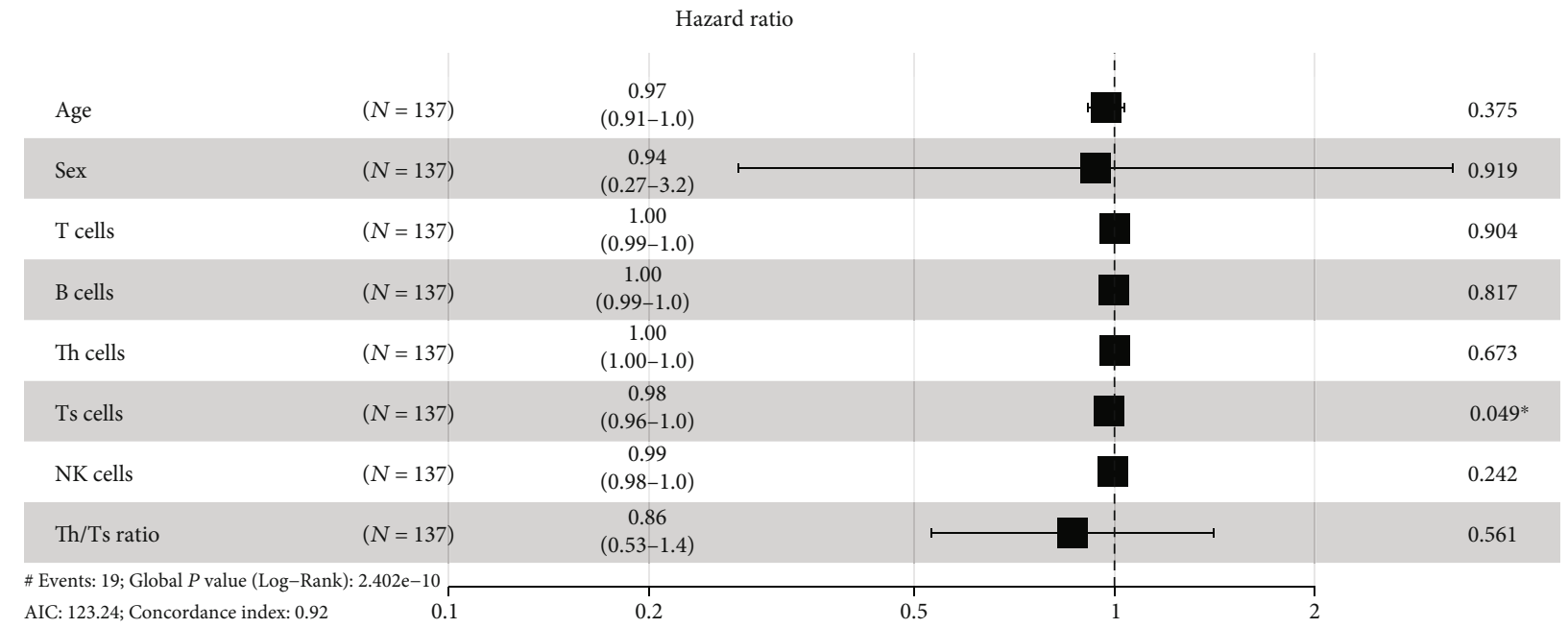

(b)

Figure 6: Multivariate Cox analyses of inflammatory cytokines (higher vs. normal or lower) and lymphocyte subsets (/ $\mu \mathrm{L})$ with deceased COVID-19.

the hyperinflammatory response, while only $S$ protein in all SARS proteins could induce the activation of IL- 8 promoter $[38,39]$. Anti-Spike-IgG (Anti-S-IgG) in SARS-CoV-2 infection would promote proinflammatory monocyte or macrophage accumulation and IL-8 production in lungs [40]. Additionally, a single center, randomised, open-label, phase 2 trial of anti-IL-8 therapy (BMS-986253) compared with Standard of Care in treating Hospitalized severe patients with COVID-19 (NCT04347226) is ongoing for improving the health condition of patients.

Hyperinflammatory cytokines may be associated with tissue injury, respiratory failure, multiple organ failure, or shock [31]. Besides, cytokines released under the innate immune responses against virus infection could also induce the release of glucocorticoids and other peptides by the neuroendocrine system, resulting in impaired immune response [31]. SARS-CoV-2 viral proteins might target several innate immune signaling proteins from pathways including the interferon (IFN) pathway, NF- $\kappa$ B pathway, and JAK/STAT signal- ing pathway $[15,41]$ that play crucial roles in excessive inflammation and immunopathology against virus infection, causing increased inflammatory cytokines/chemokines levels. Additionally, previous studies indicated that therapies using cytokines or cytokine inhibitors have been successively successful [42], and interferon $\alpha$ of antipathogenic cytokines is an officially recommended drug for treating COVID-19 in China [43]. The dysregulation of immune response would induce the hyperinflammatory even cause mortality. However, the underling role of cytokine storms in COVID-19 pathogenesis is still unclear and needs to further research.

Direct cytopathic effects and immune evasion have been proved to play important roles in disease severity of coronavirus infection [17]. Here, we demonstrated that lymphocytes and $\mathrm{T}$ cell subset counts showed significant reduction in most cases of COVID-19, but B cell counts decreased only in $28.5 \%$ of them. T cell and Ts cell counts decreased beyond the lower limit of normal range, while numbers of $\mathrm{Th}, \mathrm{B}$, and NK cells remained within normal range. In deceased 
cases, all lymphocytes and $\mathrm{T}$ cell subset counts reduced markedly below the lower limit of normal range, which were significantly lower than survivors. One previous study suggested that lymphocyte subset levels in severe cases had significantly reduced, excluding only B cells [15] which was different with our results. This might due to the fact that there were only 6 out of 8 severe cases in their study and no available immunological data in moderate cases. In our study, Th/Ts ratio elevated in $21.2 \%$ patients and was markedly higher in deceased cases than survivors. The reduction in counts of all lymphocyte subsets was correlated with both severity and mortality of COVID-19 [44], but Th/Ts ratio only correlated with mortality. However, only Ts cell was found significantly associated with deceased COVID-19 on multivariate analyses, indicating that Ts cell might be the potential predictor for deceased COVID-19, which was consistent with previous studies [13,44]. We also found that counts of lymphocyte subsets were all negatively correlated with IL-6, IL-8, and IL-10 levels. Previous studies indicated that IL- 6 could suppress normal T cell activation while IL-8 would attract neutrophil granulocytes and T lymphocytes, which might partly explain the lymphopenia [38, 39]. Besides, IL- 6 and IL- 8 induced by SARS-CoV would impair $\mathrm{T}$ cell functions on prime dendritic cells as well as viral clearance of macrophages and dendritic cells, thus causing impairment of adaptive immune response [33]. As for IL10 , it could indirectly inhibit $\mathrm{T}$ cell activation and production of T cell-derived cytokines by the inhibitory effects on APCs as well as directly suppress production of some cytokines [45]. IL-10 could also mediate direct effects on T cells, B cells, NK cells, mast cells, and eosinophils [45]. It was reported that IL-10 signaling blockade at the priming stage could induce stronger Ts cell responses, which is beneficial for treatment of chronic viruses and cancer [37]. Our study demonstrated that the depletion of lymphocyte subsets might cause hyperinflammatory response in deceased cases, resulting in overproduction of proinflammatory cytokines and cytokine storm in SARS-CoV-2 infection, which might be part of the immunogenicity of COVID-19.

Mechanism of lymphocyte reduction in deceased COVID-19 is still unclear. Previous studies revealed that lymphopenia might be correlated with apoptosis activation and P53 signaling pathway in lymphocytes [46]. Similar with SARS-CoV and MERS-CoV [47, 48], these infections could induce apoptosis in $\mathrm{T}$ cells and cause significantly decrease in numbers of peripheral lymphocyte subsets, which would further induce apoptosis in multiple organs and T lymphocytes. Moreover, different exposure doses of SARS-CoV-2 could also affect lymphocyte response. High dose exposure would cause adverse endpoints and viral clearance delay, which might be related to the inefficient $\mathrm{T}$ and $\mathrm{B}$ cell responses caused by lymphopenia, subsequently inducing cytokine storm and destructive tissue inflammation [41]. It is believed that lymphocytes, especially Th and Ts cells, serve major roles in attenuating overactivated innate immune response in SARS-CoV-2 infection [15, 49]. In this process, Th cell helps promoting virus-specific antibodies production, regulating immune responses, and mediating the activation, proliferation, and deletion of immune cells (especially Ts cells), which may result in the finding that high-level Th cell count had a strong correlation with the severity of SARS$\mathrm{CoV}$ infection [47]. Besides, Ts cells are critical for regulating viral clearance and immune-mediated injury, which can be strongly affected by lymphopenia; Ts and NK cells are essential for facilitating appropriate antiviral responses, which might be associated with the elevated level of NK group 2 member A (NKG2A) [49, 50]. Glucocorticoid treatment in COVID-19 might induce the decrease in lymphocytes [13, 15], and drugs on lymphocyte proliferation or preventing apoptosis might be beneficial for preventing lymphopenia or restoring lymphocyte numbers in severe cases [51].

Several limitations may exist in the study. Firstly, this is a retrospective study in which we only estimated the number of lymphocyte and $\mathrm{T}$ cell subsets on admission with severity and mortality in COVID-19. The percentage, temporal change, and function of lymphocyte subsets together with the dynamics of cellular immune response after SARS-CoV-2 infection might need to be elucidated by the large-sample study. Secondly, there is an impairment of immune system after SARS-CoV-2 infection that might cause coinfection with various pathogens or secondary infection, possibly influencing the effect of immune response in COVID-19.

In conclusion, SARS-CoV-2 would induce lymphopenia with decreased levels of lymphocyte subset cells, particularly Ts cells, and subsequently induce hyperinflammatory response and cytokine storm. Levels of IL-6, IL-8, IL-10, and Ts cell count might be the independent predictors of disease severity and adverse endpoints and additions to prognostic factors. Further researches on the immune pathogenesis and effect are of importance for the clinical management and development of therapeutics and vaccines of COVID-19.

\section{Data Availability}

The datasets analyzed in the study are available from our corresponding author by request.

\section{Conflicts of Interest}

The authors declare no conflicts of interest.

\section{Authors' Contributions}

NJ, ZL, TL, and QY designed the article. ZL, BY, MJ, YS, YH, YL, and YW collected and analyzed the data. NJ, ZL, and BY drafted of the manuscript. DS, PM, JZ, TL, and QY discussed and revised the manuscript. Nan Jiang and Zhijun Li contributed equally to the work.

\section{Acknowledgments}

The authors are grateful to all health workers.

\section{Supplementary Materials}

Correlation coefficient and $P$ value between cytokine profiles and lymphocyte subsets in COVID-19. (Supplementary Materials) 


\section{References}

[1] N. Zhu, D. Zhang, W. Wang, X. Li, and B. Yang, "A novel coronavirus from patients with pneumonia in China," The New England Journal of Medicine, vol. 328, no. 8, pp. 727733, 2019.

[2] W. J. Guan, Z. Y. Ni, Y. Hu et al., "Clinical characteristics of coronavirus disease 2019 in China," The New England Journal of Medicine, vol. 382, no. 18, pp. 1708-1720, 2020.

[3] R. Lu, X. Zhao, J. Li et al., "Genomic characterisation and epidemiology of 2019 novel coronavirus: implications for virus origins and receptor binding," The Lancet, vol. 395, no. 10224 , pp. 565-574, 2020.

[4] P. Zhou, X.-L. Yang, X.-G. Wang et al., "A pneumonia outbreak associated with a new coronavirus of probable bat origin," Nature, vol. 579, no. 7798, pp. 270-273, 2020.

[5] World Health Organization, Novel Coronavirus (2019- $n$ CoV) situation report-10, World Health Organization, 2020, 2020, https://apps.who.int/iris/handle/10665/330775.

[6] World Health Organization, Novel Coronavirus 2019 (2019$n \mathrm{CoV}$ ) situation report-51, World Health Organization, 2020, 2020, https://apps.who.int/iris/handle/10665/331475.

[7] World Health Orgnization, COVID-19 vaccines, 2020, https:// www.who.int/emergencies/diseases/novel-coronavirus-2019/ covid-19-vaccines.

[8] Q. Ruan, K. Yang, W. Wang, L. Jiang, and J. Song, "Clinical predictors of mortality due to COVID-19 based on an analysis of data of 150 patients from Wuhan, China," Intensive Care Medicine, vol. 46, no. 5, pp. 846-848, 2020.

[9] T. Chen, D. Wu, H. Chen et al., "Clinical characteristics of 113 deceased patients with coronavirus disease 2019: retrospective study," BMJ, vol. 368, p. m1091, 2020.

[10] F. Zhou, T. Yu, R. Du et al., "Clinical course and risk factors for mortality of adult inpatients with COVID-19 in Wuhan, China: a retrospective cohort study," The Lancet, vol. S01406736, no. 20, p. 30566, 2020.

[11] C. Huang, Y. Wang, X. Li et al., "Clinical features of patients infected with 2019 novel coronavirus in Wuhan, China," The Lancet, vol. 395, no. 10223, pp. 497-506, 2020.

[12] Z. Xu, L. Shi, Y. Wang et al., "Pathological findings of COVID-19 associated with acute respiratory distress syndrome," The Lancet Respiratory Medicine, vol. 8, no. 4, pp. 420-422, 2020.

[13] F. Wang, J. Nie, H. Wang et al., "Characteristics of peripheral lymphocyte subset alteration in COVID-19 pneumonia," The Journal of Infectious Diseases, vol. 221, no. 11, pp. 17621769, 2020.

[14] C. Qin, L. Zhou, Z. Hu et al., "Dysregulation of immune response in patients with COVID-19 in Wuhan, China," Clinical Infectious Diseases, vol. 71, no. 15, pp. 762-768, 2020.

[15] G. Chen, D. Wu, W. Guo et al., "Clinical and immunological features of severe and moderate coronavirus disease 2019," The Journal of Clinical Investigation, vol. 130, no. 5, pp. 2620-2629, 2020.

[16] National Health Commission of the People's Republic of China, The Seventh Revised Trial Version of the Novel Coronavirus Pneumonia Diagnosis and Treatment Guidance, 2020, ht tp://www.nhc.gov.cn/yzygj/s 7652 m/202003/ a31191442e29474b98bfed5579d5af95.shtml.

[17] R. Channappanavar and S. Perlman, "Pathogenic human coronavirus infections: causes and consequences of cytokine storm and immunopathology," Seminars in Immunopathology, vol. 39, no. 5, pp. 529-539, 2017.

[18] P. Goyal, J. J. Choi, L. C. Pinheiro et al., "Clinical characteristics of Covid-19 in New York City," New England Journal of Medicine, vol. 382, no. 24, pp. 2372-2374, 2020.

[19] B. Bode, V. Garrett, J. Messler et al., "Glycemic characteristics and clinical outcomes of COVID-19 patients hospitalized in the United States," Journal of Diabetes Science and Technology, vol. 14, no. 4, pp. 813-821, 2020.

[20] Y. Yan, Y. Yang, F. Wang et al., "Clinical characteristics and outcomes of patients with severe covid-19 with diabetes," BMJ Open Diabetes Research \& Care, vol. 8, no. 1, article e001343, 2020.

[21] L. Zhu, Z. G. She, X. Cheng et al., "Association of blood glucose control and outcomes in patients with COVID-19 and preexisting type 2 diabetes," Cell Metabolism, vol. 31, no. 6, pp. 1068-1077.e3, 2020.

[22] Y. Liu, D. Xuebei, J. Chen et al., "Neutrophil-to-lymphocyte ratio as an independent risk factor for mortality in hospitalized patients with COVID-19," Journal of Infection, vol. 81, no. 1, pp. e6-e12, 2020.

[23] T. Guo, Y. Fan, M. Chen et al., "Cardiovascular implications of fatal outcomes of patients with coronavirus disease 2019 (COVID-19)," JAMA Cardiology, vol. 5, no. 7, pp. 811-818, 2020.

[24] L. Yan, H.-T. Zhang, J. Goncalves et al., "An interpretable mortality prediction model for COVID-19 patients," Nature Machine Intelligence, vol. 2, no. 5, pp. 283-288, 2020.

[25] M. Berhane, M. Melku, A. Amsalu, B. Enawgaw, Z. Getaneh, and F. Asrie, "The role of neutrophil to lymphocyte count ratio in the differential diagnosis of pulmonary tuberculosis and bacterial community-acquired pneumonia: a cross-sectional study at Ayder and Mekelle Hospitals, Ethiopia," Clinical Laboratory, vol. 65, 2019.

[26] Z. Huang, Z. Fu, W. Huang, and K. Huang, "Prognostic value of neutrophil-to-lymphocyte ratio in sepsis: a meta-analysis," The American Journal of Emergency Medicine, vol. 38, no. 3, pp. 641-647, 2020.

[27] J. H. Ko, G. E. Park, J. Y. Lee et al., "Predictive factors for pneumonia development and progression to respiratory failure in MERS-CoV infected patients," The Journal of Infection, vol. 73, no. 5, pp. 468-475, 2016.

[28] S. H. Alfaraj, J. A. Al-Tawfiq, A. Y. Assiri, N. A. Alzahrani, A. A. Alanazi, and Z. A. Memish, "Clinical predictors of mortality of Middle East respiratory syndrome coronavirus (MERS-CoV) infection: a cohort study," Travel Medicine and Infectious Disease, vol. 29, pp. 48-50, 2019.

[29] J.-Y. CHIEN, P.-R. HSUEH, W.-C. CHENG, C. J. YU, and P.C. YANG, "Temporal changes in cytokine/chemokine profiles and pulmonary involvement in severe acute respiratory syndrome," Respirology, vol. 11, no. 6, pp. 715-722, 2006.

[30] B. G. Chousterman, F. K. Swirski, and G. F. Weber, "Cytokine storm and sepsis disease pathogenesis," Seminars in Immunopathology, vol. 39, no. 5, pp. 517-528, 2017.

[31] X. Cao, "COVID-19: immunopathology and its implications for therapy," Nature Reviews Immunology, vol. 20, no. 5, pp. 269-270, 2020.

[32] J. B. Moore and C. H. June, "Cytokine release syndrome in severe COVID-19,” Science, vol. 368, no. 6490, pp. 473-474, 2020.

[33] P. Sarzi-Puttini, V. Giorgi, S. Sirotti et al., "COVID-19, cytokines and immunosuppression: what can we learn from severe 
acute respiratory syndrome?," Clinical and Experimental Rheumatology, vol. 38, no. 2, pp. 337-342, 2020.

[34] Y. F. Tu, C. S. Chien, A. A. Yarmishyn et al., "A review of SARS-CoV-2 and the ongoing clinical trials," International Journal of Molecular Sciences, vol. 21, no. 7, p. 2657, 2020.

[35] C. Zhang, Z. Wu, J. W. Li, H. Zhao, and G. Q. Wang, "Cytokine release syndrome in severe COVID-19: interleukin-6 receptor antagonist tocilizumab may be the key to reduce mortality," International Journal of Antimicrobial Agents, vol. 55, no. 5, p. 105954, 2020.

[36] W. H. Mahallawi, O. F. Khabour, Q. Zhang, H. M. Makhdoum, and B. A. Suliman, "MERS-CoV infection in humans is associated with a pro-inflammatory Th1 and Th17 cytokine profile," Cytokine, vol. 104, pp. 8-13, 2018.

[37] G. Ni, T. Wang, S. Walton et al., "Manipulating IL-10 signalling blockade for better immunotherapy," Cellular Immunology, vol. 293, no. 2, pp. 126-129, 2015.

[38] A. M. Klok, L. Luyendijk, M. J. Zaal, A. Rothova, C. E. Hack, and A. Kijlstra, "Elevated serum IL-8 levels are associated with disease activity in idiopathic intermediate uveitis," The British Journal of Ophthalmology, vol. 82, no. 8, pp. 871-874, 1998.

[39] Y. J. Chang, C. Y. Liu, B. L. Chiang, Y. C. Chao, and C. C. Chen, "Induction of IL-8 release in lung cells via activator protein-1 by recombinant baculovirus displaying severe acute respiratory syndrome-coronavirus spike proteins: identification of two functional regions," Journal of immunology, vol. 173, no. 12, pp. 7602-7614, 2004.

[40] Y. Fu, Y. Cheng, and Y. Wu, "Understanding SARS-CoV-2mediated inflammatory responses: from mechanisms to potential therapeutic tools," Virologica Sinica, vol. 35, no. 3, pp. 266-271, 2020.

[41] A. K. Azkur, M. Akdis, D. Azkur et al., "Immune response to SARS-CoV-2 and mechanisms of immunopathological changes in COVID-19," Allergy, vol. 75, no. 7, pp. 15641581, 2020.

[42] J. M. Shim, J. Kim, T. Tenson, J.-Y. Min, and D. E. Kainov, "Influenza virus infection, interferon response, viral counter-response, and apoptosis," Viruses, vol. 9, no. 8, p. 223, 2017.

[43] Y. Liu, C. Zhang, F. Huang et al., "Elevated plasma levels of selective cytokines in COVID-19 patients reflect viral load and lung injury," National Science Review, vol. 7, no. 6, pp. 1003-1011, 2020.

[44] D. Li, Y. Chen, H. Liu et al., "Immune dysfunction leads to mortality and organ injury in patients with COVID-19 in China: insights from ERS-COVID-19 study," Signal Transduction and Targeted Therapy, vol. 5, no. 1, p. ???, 2020.

[45] R. P. Donnelly, H. Dickensheets, and D. S. Finbloom, "The interleukin-10 signal transduction pathway and regulation of gene expression in mononuclear phagocytes," Journal of Interferon \& Cytokine Research, vol. 19, no. 6, pp. 563-573, 1999.

[46] Y. Xiong, Y. Liu, L. Cao et al., "Transcriptomic characteristics of bronchoalveolar lavage fluid and peripheral blood mononuclear cells in COVID-19 patients," Emerg Microbes Infect, vol. 9, no. 1, pp. 761-770, 2020.

[47] C. K. Li, H. Wu, H. Yan et al., "T cell responses to whole SARS coronavirus in humans," Journal of immunology, vol. 181, no. 8, pp. 5490-5500, 2008.

[48] H. Chu, J. Zhou, B. H.-Y. Wong et al., "Middle East respiratory syndrome coronavirus efficiently infects human primary $\mathrm{T}$ lymphocytes and activates the extrinsic and intrinsic apoptosis pathways," The Journal of Infectious Diseases, vol. 213, no. 6, pp. 904-914, 2016.

[49] M. E. Schmidt and S. M. Varga, "The CD8 T cell response to respiratory virus infections," Frontiers in Immunology, vol. 9, p. 678, 2018.

[50] M. Zheng, Y. Gao, G. Wang et al., "Functional exhaustion of antiviral lymphocytes in COVID-19 patients," Cellular \& Molecular Immunology, vol. 17, no. 5, pp. 533-535, 2020.

[51] J. F. Bermejo-Martin, R. Almansa, R. Menéndez, R. Mendez, D. J. Kelvin, and A. Torres, "Lymphopenic community acquired pneumonia as signature of severe COVID-19 infection," The Journal of Infection, vol. 80, no. 5, pp. e23-e24, 2020. 